\title{
UNA ESCULTURA INÉDITA DE SAN ROQUE DEL CÍRCULO DE BALDUQUE, RECUPERADA EN TENERIFE
}

\author{
José Cesáreo López Plasencia \\ Consejería de Educación y Universidades. Gobierno de Canarias, Santa Cruz de Tenerife \\ j_cesareo@hotmail.com
}

\section{Resumen}

En este artículo estudiamos una escultura lignaria de san Roque de Montpellier que pertenece a la parroquia matriz de La Concepción, en Realejo Bajo, Los Realejos (Tenerife). La imagen, que fue venerada en el extinto convento franciscano de Santa Lucía, en el mismo municipio, ha sido recientemente restaurada, y sus grafismos permiten relacionarla con el arte de Roque de Balduque, célebre escultor y entallador flamenco, activo en Sevilla entre 1534 y 1561 y una de las figuras más destacadas de la escultura española del siglo XVI.

Palabras clave: san Roque, Realejo Bajo, escultura, siglo xvi, Roque de Balduque.

\section{AN UNKNOWN SCULPTURE OF SAINT ROCH, FROM BALDUQUE'S CIRCLE, RECOVERED IN TENERIFE}

\section{Abstract}

In this paper we study a wood sculpture representing Saint Roch of Montpellier that belongs to the parish church of The Immaculate Conception, in Realejo Bajo, Los Realejos (Tenerife). The religious effigy, which was venerated in the extinct Franciscan Convent of Saint Lucy, in the same town, has recently been restored. Its art features allow us to relate this simulacrum to the art of the well-known Flemish sculptor and woodcarver Roque de Balduque, who worked in Seville from 1534 to 1561 and is one of the most prominent figures in $16^{\text {th }}$-century Spanish sculpture.

KeYwords: Saint Roch, Realejo Bajo, sculpture, $16^{\text {th }}$ century, Roque de Balduque. 


\section{LA ESCULTURA DE SAN ROQUE Y SU PROCEDENCIA}

Recientemente se ha presentado una imagen que figura a san Roque (Montpellier, 1295-Voghera, 1327), en la parroquia matriz de La Concepción de Realejo Bajo (Tenerife) (fig. 1) ${ }^{1}$. Se trata de una escultura realizada en madera policromada y estofada $(80 \mathrm{~cm}$.), sobre peana de madera en su color $(29 \times 12 \mathrm{~cm}$.), que muestra al santo de Montpellier ataviado con el atuendo de peregrino, denominado sarrocchino, ya que no hemos de olvidar que el santo realizó peregrinaciones a Roma, Jerusalén y Santiago de Compostela. Por este motivo, el sagrado simulacro se nos presenta con túnica, capa corta, calzas (fig. 2) y tocado con sombrero de ala ancha (fig. 3). En su mano derecha porta el bordón de peregrino con la calabaza para el agua, mientras que con la mano izquierda levanta la túnica que permite ver en el muslo derecho el bubón pestilente o úlcera, signo de la peste que contrajo en la ciudad de Acquapendente (Lazio) cuando socorría a los apestados. En realidad, según relatan sus hagiógrafos, la úlcera de la enfermedad se localizaba en la ingle del peregrino, pero los artistas, por respeto o decencia, optaron por situarla en el muslo. Junto a su pierna izquierda se sitúa una figura infantil que señala la úlcera (fig. 4), talla que ocupa el lugar del ángel enfermero que lo suele acompañar en sus representaciones desde el siglo $\mathrm{xv}$, ser angélico enviado por Dios para que le curase y confortara en el bosque de Piacenza o Plasencia, capital de la provincia homónima en la región de EmiliaRomaña, lugar al que acudió para morir en soledad y no contagiar a nadie (Interián de Ayala 1782, pp. 348-350; Vorágine 1997, p. 954; Réau 1998, pp. 147-153; Torrico Lorenzo 2017, pp. 105-116). La pequeña escultura, al no haber sido efigiada con alas, cabe la posibilidad de identificarla con una alegoría del alma cristiana, que acompaña al santo en estos difíciles momentos de su vida. Asimismo, hemos de indicar que en esta figuración no se ha incluido el perro con el pan en sus fauces -muy frecuente en la iconografía de san Roque-, animal que alimentó cada día al santo cuando éste se retiró contagiado al referido bosque de Piacenza.

En cuanto a la procedencia de la obra, la misma, según señalara el Dr. Castro Brunetto en su inédita tesis doctoral sobre la iconografía franciscana en Canarias (Castro Brunetto 1993, p. 469), se localizaba en el «retablo de San Roque que pertenece a la Casa de Alzola», en el antiguo convento de franciscanos descalzos de Santa Lucía, en Los Realejos, estando flanqueada por las tallas de San Pedro de Alcántara, hoy en la parroquia del Apóstol Santiago de Los Realejos, y Santa Teresa de Jesús, efigie cuyo paradero actual desconocemos. Esta información figura en un inventario de los bienes conventuales, redactado en 1821 con motivo de la desamortización del cenobio realejero. Del referido documento se colige que el retablo de san Roque fue llevado a cabo por deseo del ilustre linaje de los Alzola, familia ligada al convento de Santa Lucía desde sus orígenes en 1610, al igual que al acontecer his-

${ }^{1}$ La escultura fue presentada y bendecida en la citada parroquia, el lunes 16-viri-2021, memoria litúrgica de san Roque, por el Rvdo. D. Marcos Antonio García Luis-Moleiro, párroco de Realejo Bajo. 


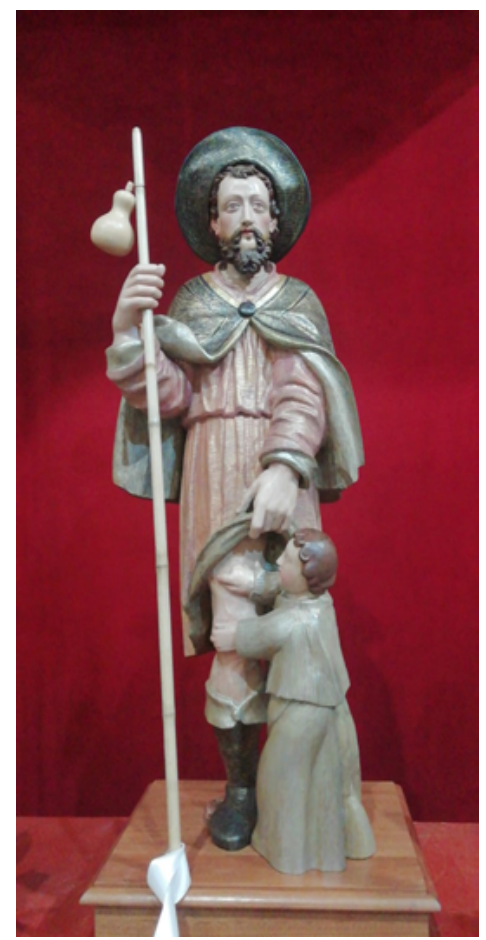

Fig. 1. Círculo de Roque de Balduque, San Roque de Montpellier, ca. 1560-1580, $80 \mathrm{~cm}$., parroquia matriz de La Concepción, Realejo Bajo, Tenerife.

[Foto: J. N. Rodríguez Hernández].

tórico, religioso y cultural de Realejo Bajo. No en vano, a principios del siglo XvII, Esteban del Hoyo Solórzano y Mesa y su esposa Jerónima de Ayala Jovel y Guzmán fueron los propietarios de la rica hacienda y ermita de la Virgen del Socorro, ubicada en la costa del pueblo, cuyos retratos como donantes, junto a los de sus hijos, figuran en la predela del retablo manierista del citado eremitorio mariano, que ellos habían fundado (Fernández de Béthencourt 1959, pp. 911-912; González y González 1997, pp. 24-34, láms. I-IV).

Precisamente, fue el citado caballero Esteban del Hoyo Solórzano y Mesa, capitán de Infantería Española, quien trajo y colocó la talla de su devoto abogado san Roque en el retablo que al santo de Montpellier había dedicado en la iglesia franciscana. La colocación de la imagen tuvo lugar entre 1610, año de fundación del convento, y 1619, puesto que en un codicilo, datado en Realejo Bajo el 19 de septiembre de ese último año, el donante de la talla indicó lo siguiente:

... se le diga en cada ańo perpetuamente una misa cantada en el convento del Señor San Francisco de este dicho lugar en el altar que a su costa tiene hecho, advocación del Señor San Roque, y a su advocación de en sus día y octavario [...] que tengo 


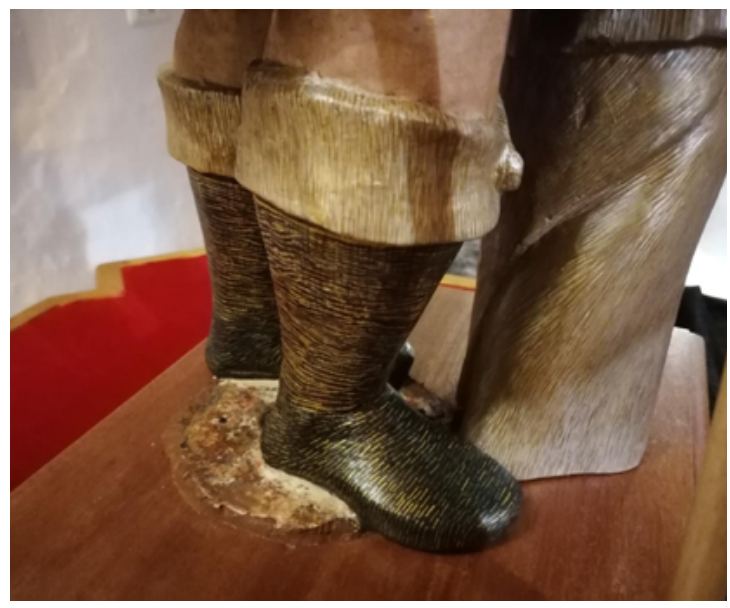

Fig. 2. Círculo de Roque de Balduque,

San Roque de Montpellier (detalle), parroquia matriz de La Concepción, Realejo Bajo, Tenerife.

[Foto: parroquia de La Concepción].

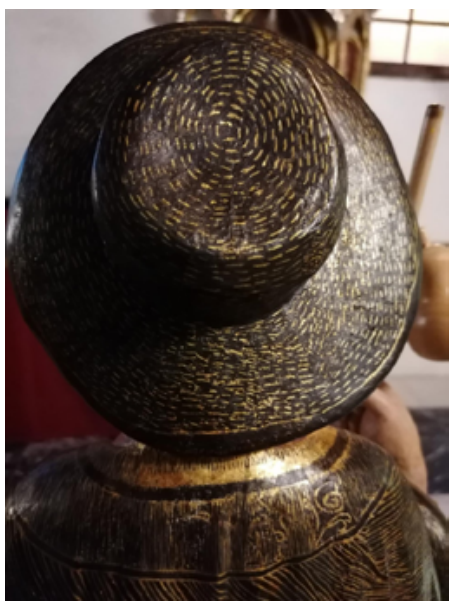

Fig. 3. Círculo de Roque de Balduque, San Roque de Montpellier (detalle), parroquia matriz de La Concepción, Realejo Bajo, Tenerife.

[Foto: J.C. López Plasencia].

puesto al Señor San Roque, mi abogado [...] y también les di el bulto del que está en el dicho altar.

Por otra parte, su hija Juana del Hoyo Solórzano y Ayala, en su testamento fechado el 25 de enero de 1639, declaró:

... que por cuanto el capitán Esteban del Hoyo, mi padre, y doña Jerónima de Ayala, mi madre, y yo, tenemos devoción al bienaventurado San Roque, al cual hicimos traer de bulto y le tenemos en un altar que hicimos en el convento de mi Padre San Francisco; el cual mandaron los dichos mis padres hacer [...] (Santana Rodríguez 2006, p. 58).

Una vez clausurado el convento a raíz de la desamortización, la talla pasó a un domicilio cercano al cenobio, no teniéndose información sobre la misma hasta que la feligresa dońa Isabel Albelo Hernández (+ 2000), que había recibido la efigie de sus padres, la entregó al entonces párroco de Realejo Bajo, Rvdo. D. Ramón Padilla Brito, a comienzos de la década de los ochenta del pasado siglo xx. El sacerdote depositó la imagen, en precario estado de conservación (fig. 5), en dependencias de la casa parroquial, según se dio a conocer en el estudio dedicado al extinto convento franciscano (López Plasencia 2000, p. 144).

Posteriormente, en 2006, la talla figuró en el catálogo de la exposición «Roque de Montpellier. Iconografía de los santos protectores de la peste en Cana- 


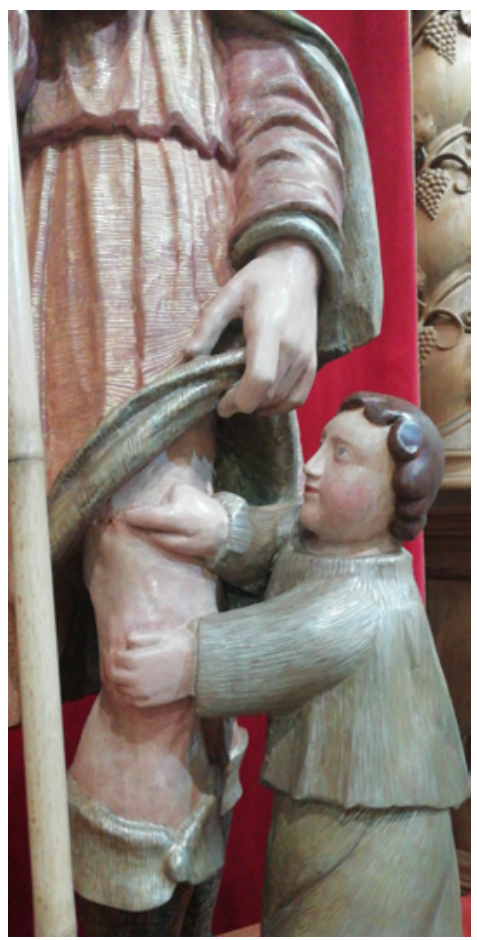

Fig. 4. Círculo de Roque de Balduque, San Roque de Montpellier (detalle), parroquia matriz de La Concepción, Realejo Bajo, Tenerife. [Foto: J.N. Rodríguez Hernández].

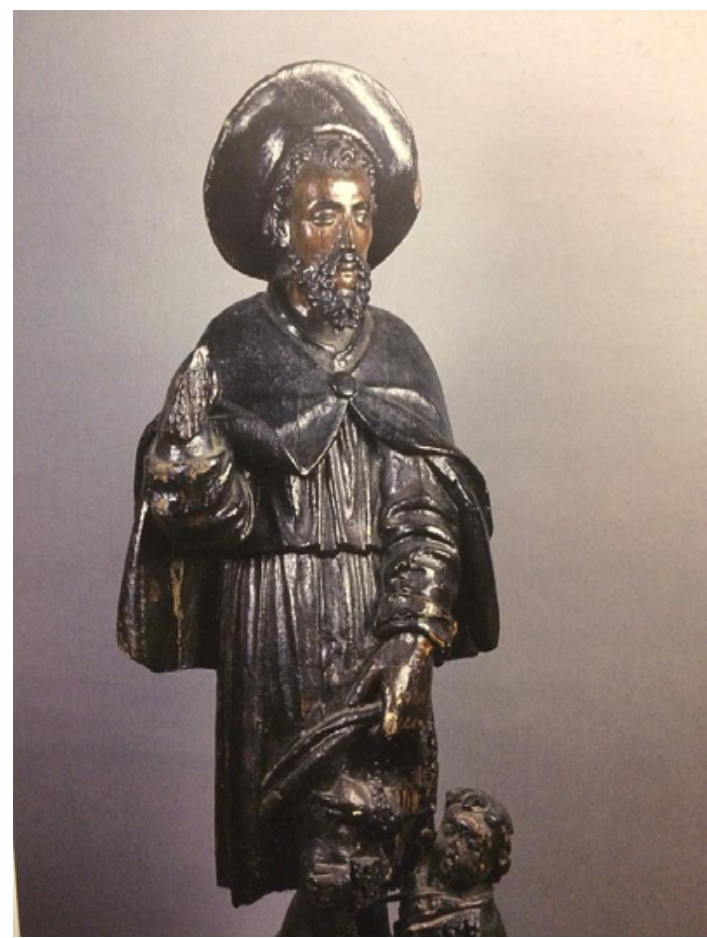

Fig. 5. Círculo de Roque de Balduque, San Roque de Montpellier (estado previo a la restauración), parroquia matriz de La Concepción, Realejo Bajo, Tenerife.

[Foto: Parroquia de La Concepción].

rias», celebrada en la Villa y Puerto de Garachico ${ }^{2}$, indicando el autor de la ficha catalográfica que la imagen se encontraba en la casa parroquial de La Concepción de Realejo Bajo, y que «es ahora cuando se da a conocer historiográficamente su existencia» (Hernández González 2006, p. 230). Nada más lejos de la realidad, puesto que, según se indicó en líneas precedentes, en el año 2000 ya se había informado de su presencia, procedencia y entrega al párroco de Realejo Bajo, referencia que no fue incluida por el autor en su texto.

${ }^{2}$ La escultura no pudo ser expuesta en la muestra de Garachico, ya que tuvo que ser desinsectada urgentemente debido a los xilófagos que la atacaban en aquel momento. 


\section{NOTAS SOBRE SU PROCESO DE RESTAURACIÓN-CONSERVACIÓN}

Hace unos dos años, y merced a una subvención concedida por el Área de Cultura del Excmo. Cabildo de Tenerife, así como a los desvelos de la parroquia por su recuperación, la escultura fue retirada del templo para ser sometida a un proceso de restauración-conservación, labores que le fueron encomendadas a la restauradora-conservadora doña Patricia Padrón Sosa, licenciada en Bellas Artes y máster en Conservación y Restauración de Bienes Culturales por la Universidad Politécnica de Valencia. Esta profesional, tras la desinsectación de la talla y el profundo trabajo de limpieza llevado a cabo en la misma durante año y medio, ha logrado recuperar la policromía y los estofados en oro y plata que ennoblecen la efigie en su atuendo y carnación. Según han desvelado los estudios, la policromía original estaba oculta bajo trece capas de barniz, pintura y consolidantes, indicando la sexta capa que la escultura había sido repolicromada en el siglo xvinI, a base de motivos florales sobre fondo marrón. Esta segunda policromía ocultaba el estofado original en pan de oro y plata, éste último localizado en las mangas y calzas, y conservado en un 30\%. Tras el proceso de limpieza, se procedió a estucar la escultura y a reintegrar la policromía. La reintegración cromática se realizó mediante la técnica del rigatino, a base de rayas muy finas, utilizándose acuarela para reintegrar el pan de plata. Según indicó la profesional, la policromía original se pudo recuperar sobre todo en la capa, que presentaba un mejor estado de conservación, al igual que el sombrero. Finalmente, la restauradora decidió dejar una zona como testigo, localizada en la túnica.

Por otra parte, fue necesaria la realización de algunas piezas lignarias desaparecidas, caso de la mano derecha del santo, el bordón, la calabaza y parte de la efigie del niño, cuyas piernas, al igual que la peana, habían desaparecido por acción de los insectos xilófagos. La zona inferior de la talla infantil, que había quedado hueca por los referidos insectos, se pudo reconstruir a partir del dibujo y las curvas que presenta su torso ${ }^{3}$.

\section{UNA OBRA PROBABLE DEL CÍRCULO DE ROQUE DE BALDUQUE}

Con respecto a su filiación artística, hemos de indicar que relacionar la obra con algún artista o taller en concreto, en principio, se convierte en tarea harto compleja, puesto que, según nos ha manifestado el Dr. Romero Torres ${ }^{4}$, la policromía actual no parece ser la original y los plegados de la vestimenta parecen haber sido

${ }^{3}$ El trabajo desarrollado en la efigie, durante dos años, fue explicado por la restauradora en la conferencia que dictó en la parroquia matriz de Realejo Bajo, el viernes 20-vIII-2021. Su intervención se encuentra disponible en https://www.facebook.com/parroquiaconcepcion.losrealejos/ videos/392803932190845 (consulta: 7-X-2021).

${ }^{4}$ Información facilitada por el Dr. D. José Luis Romero Torres al autor de este texto, el jueves 12-vIII-2021. 


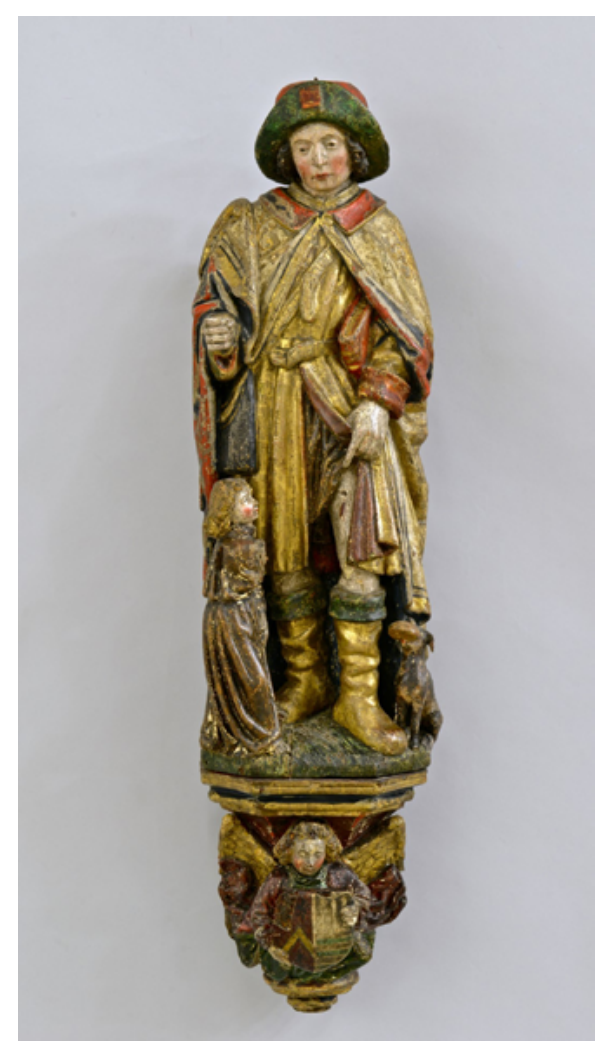

Fig. 6. Taller de Malinas, San Roque de Montpellier, ca. 1520-1525, 73 cm., Museo Hof van Busleyden (n. ${ }^{\circ}$ inv. OCMWB0003), Malinas, Bélgica

[Foto: CMuseo Hof van Busleyden].

retallados. A esto hay que añadir que algunos elementos originales, como la mano derecha del santo y parte de la escultura del niño, se han perdido y han tenido que ser tallados de nuevo. Por estos motivos, en una primera visión de la talla tan solo podemos señalar que nos hallamos ante un simulacro que, debido a su rigidez un tanto arcaizante y otros grafismos, pudo haber salido de un obrador hispalense hacia la segunda mitad del Quinientos.

No obstante, al analizar más detenidamente la efigie, a nuestro juicio, la misma evoca en cierto modo la manera de laborar y los tipos iconográficos de ascendencia medieval del insigne maestro flamenco afincado en Sevilla Roque de Balduque (doc. 1534-1561), artista que -merced al uso de estampas de Alberto Durero y Marco Antonio Raimondi, entre otros autores- supo combinar sabiamente el naturalismo gótico del norte de Europa durante la Baja Edad Media con las novedades que arribaron de la Italia renacentista (Estella 2019, p. 85), y que tiene el honor de ser considerado por la historiografía artística el fundador de la escuela sevillana 


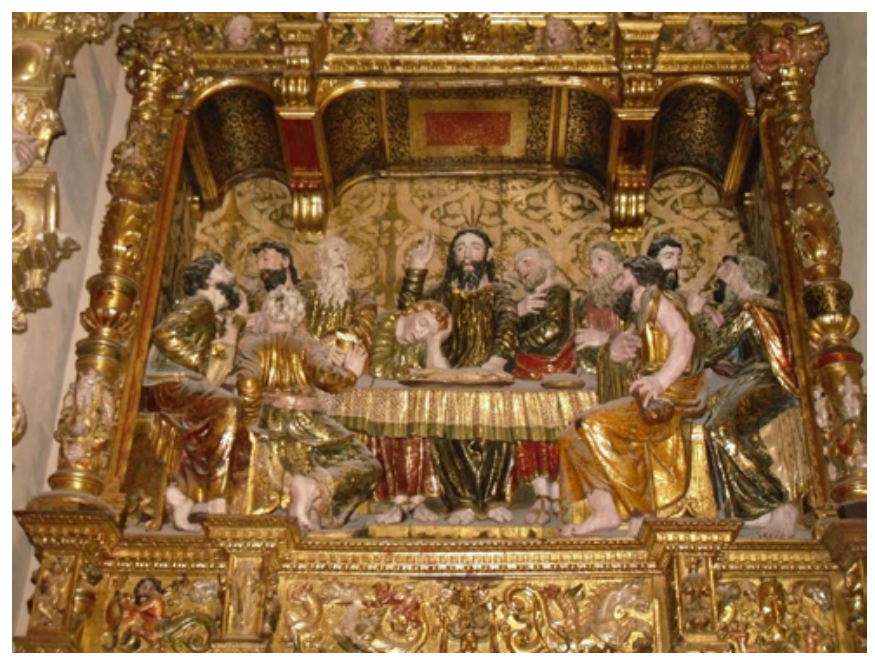

Fig. 7. Atribuido a Roque de Balduque, Santa Cena, 1554, parroquia de San Pedro Apóstol, Arcos de la Frontera, Cádiz [Foto: https://mapio.net/pic/p-40104609/].

de escultura 5 . Sus modelos, especialmente los de la Virgen con el Niño en brazos y el Crucificado (Roda Peña 2018, pp. 21-25), tuvieron gran arraigo en el antiguo Reino de Sevilla, y fueron difundidos por todo el territorio hispalense y ultramar, durante la segunda mitad del siglo XVI, por miembros vinculados a su importante obrador y otros seguidores que admiraron su estilo. Éste es el caso, entre otros, de Pedro de Heredia, Juan de Villalba o su discípulo más aventajado Juan Giralte (doc. 1561-1574), maestro también flamenco que finalizó los trabajos que el escultor de Hertogenbosch dejó inconclusos cuando acaeció su óbito, en marzo de 1561 (Estella 1975, p. 225; Palomero Páramo 1983, pp. 160-164; Gómez Sánchez 2006, pp. 74-78; Santos Márquez 2007, pp. 83-86; Recio Mir 2009, p. 105; Roda Peña 2018, p. 25; Rojas-Marcos González 2020, pp. 418-423).

Hemos de señalar que el año de la muerte de Balduque constituye, como ya se ha advertido, una fecha clave en la historia de la estatuaria hispalense, no en vano supuso el paso de la dicción plástica nórdica, plasmada por el escultor flamenco en su producción, a la maniera o fina estética de gusto italianizante -más concretamente florentina- de la que hicieron gala otros artífices con posterioridad, espe-

5 Para conocer la trayectoria del escultor y entallador se puede consultar, entre otros autores, a Gestoso y Pérez 1908, vol. III, p. 91-95; Floriano Cumbreño 1940-1941, pp. 85-95; Hernández Díaz 1944, II, 41-55 y 79-113; Estella 1975, pp. 225-242; Bernales Ballesteros 1977a, pp. 349-371; Palomero Páramo 1983, pp. 134-159; Recio Mir 2009, pp. 100-106; Albardonedo Freire 2012, pp. $795-$ 804; Santos Márquez 2017, pp. 393-404; Rojas-Marcos González 2020, pp. 407-425. 


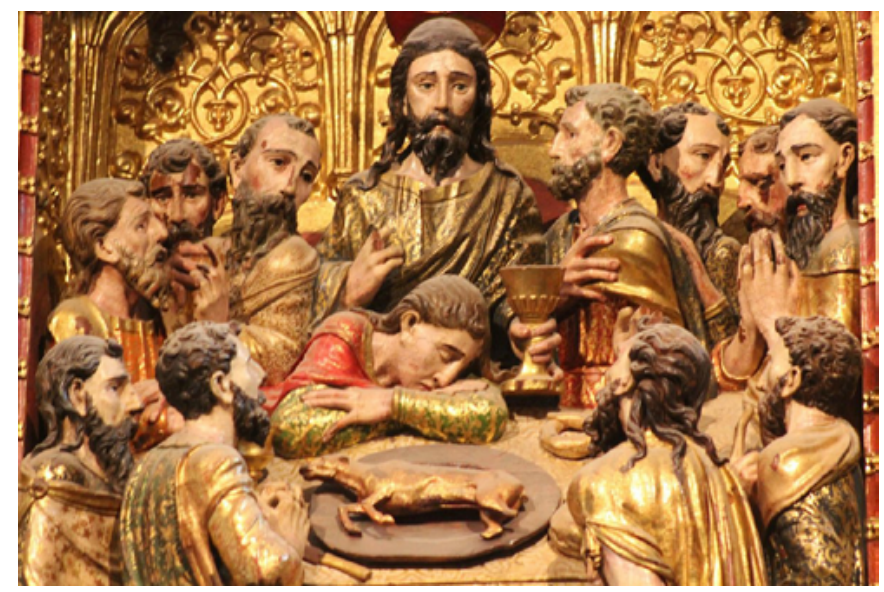

Fig. 8. Roque de Balduque, Santa Cena, 1558-1560, parroquia matriz de San Juan Bautista, Marchena, Sevilla [Foto: parroquia de San Juan Bautista].

cialmente el salmantino Juan Bautista Vázquez el Viejo (Roda Peña 2010, p. 275; González Begines 2021, pp. 14-15).

El tipo iconográfico del simulacro que analizamos, como ya hemos señalado, remite en última instancia a modelos quinientistas de la escuela germano-flamenca, que entroncan a su vez con la plástica bajomedieval, los cuales gozaron de gran aceptación entre la comitencia. En este sentido, es posible emparentar el modelo del San Roque de Los Realejos con diversas efigies salidas de los talleres de los antiguos Países Bajos, caso, entre otras muchas, de la talla anónima $(73 \mathrm{~cm}$.) salida de un taller de la floreciente ciudad de Malinas, antigua capital de los Países Bajos Borgoñones, hacia 1520-1525, la cual, hoy conservada en el malinense Museo Hof van Busleyden (n. ${ }^{\circ}$ inv. OCMWB0003), procede de la capilla del Hospital de Nuestra Señora de Malinas (Halsema-Kubes 1971, pp. 183-188). La figuración, aunque muestra al terciario franciscano de Montpellier imberbe, lo representa también en una postura recta, tocado con el sombrero de peregrino, en contrapposto, acompañado del ángel carente de alas y con una expresión que combina tristeza y melancolía en sus grandes ojos (fig. 6).

En la escultura de Los Realejos, algunos estilemas como la postura recta del cuerpo, rota por la pierna derecha que flexiona y adelanta ligeramente, marcando un suave contrapposto; las vestiduras de verticales pliegues, que no hacen sino incrementar la esbeltez de la figura, recordando la estatuaria tardogótica de herencia borgoñona del francés Lorenzo Mercadante de Bretaña (doc. 1446-1468) (Laguna Paúl 2017, pp. 290-325); la talla de la cabeza, característica del comedio del Quinientos hispalense; el rostro ovalado, de progenie nórdica, con grandes ojos de expresión melancólica y cierta tristeza, nariz recta y boca pequeña; así como algunos rasgos perceptibles en el modelado del cabello y barba -también presentes en la manera de laborar de algunos escultores activos en la Castilla de la época- (Bernales Balleste- 


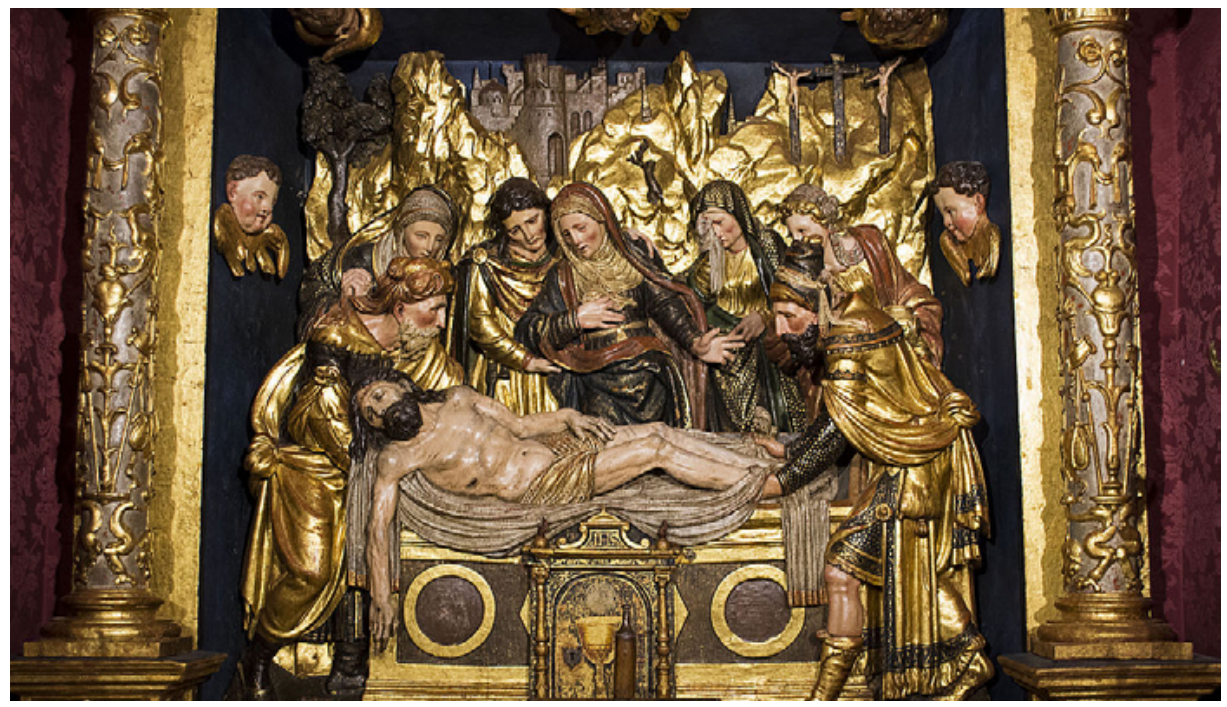

Fig. 9. Atribuido a Roque de Balduque, Lamentación sobre Cristo muerto, ca. 1550, Colegiata de La Asunción, Osuna, Sevilla [Foto: archivo del autor].

ros 1977b, pp. 36-38; Torre Ruiz 1992, pp. 31-33; Porres Benavides 2018, pp. 317340), hacen factible vincular el San Roque realejero a la plástica balduquiana, cuyas resonancias llegaron al último tercio de la centuria quinientista.

En este sentido, resulta factible relacionar la talla realejera con algunas esculturas masculinas salidas de las gubias de Balduque o atribuidas con sólidos fundamentos estéticos a su gran obrador, obras que presentan varios de los estilemas antes referidos. Éste es el caso del tratamiento del cabello y la barba en las imágenes del Cristo y los apóstoles del relieve de la Santa Cena, de la parroquia de San Pedro Apóstol en Arcos de la Frontera (Cádiz) (fig. 7); en la obra homónima (1558-1560) incluida en el retablo de la capilla del sagrario de la parroquia matriz de San Juan Bautista, de Marchena (Sevilla) (fig. 8), o en la talla del Simón de Cirene tocado con sombrero que acompańa a Nuestro Padre Jesús Cansado, en el mismo templo marchenero, efigies que muestran plegados angulosos y gestos manieristas, recordando la plástica tardogótica (Ravé 2007, pp. 30-33; Hernández González 2011, p. 84). Asimismo, encontramos otras concomitancias estilísticas en las representaciones de los Santos Varones - plasmados como el santo de Los Realejos con ovalados rostros y nariz recta- que figuran en el relieve de la Lamentación sobre Cristo muerto (ca. 1550) custodiado en el panteón ducal de la colegiata sevillana de la Asunción, en Osuna (fig. 9) (Palomero Páramo 1983, pp. 134-159; Rodríguez-Buzón 2012, p. 131; Santos Márquez 2017, p. 394) (fig.1); así como en la obra homónima que atribuida a Balduque, y procedente de la colección del pintor Luis Masriera, se conserva en el fondo del Institute of Old Masters Research de Madrid, datada hacia 1550 (fig. 10) (Parrado del Olmo 2019, pp. 334-337). 


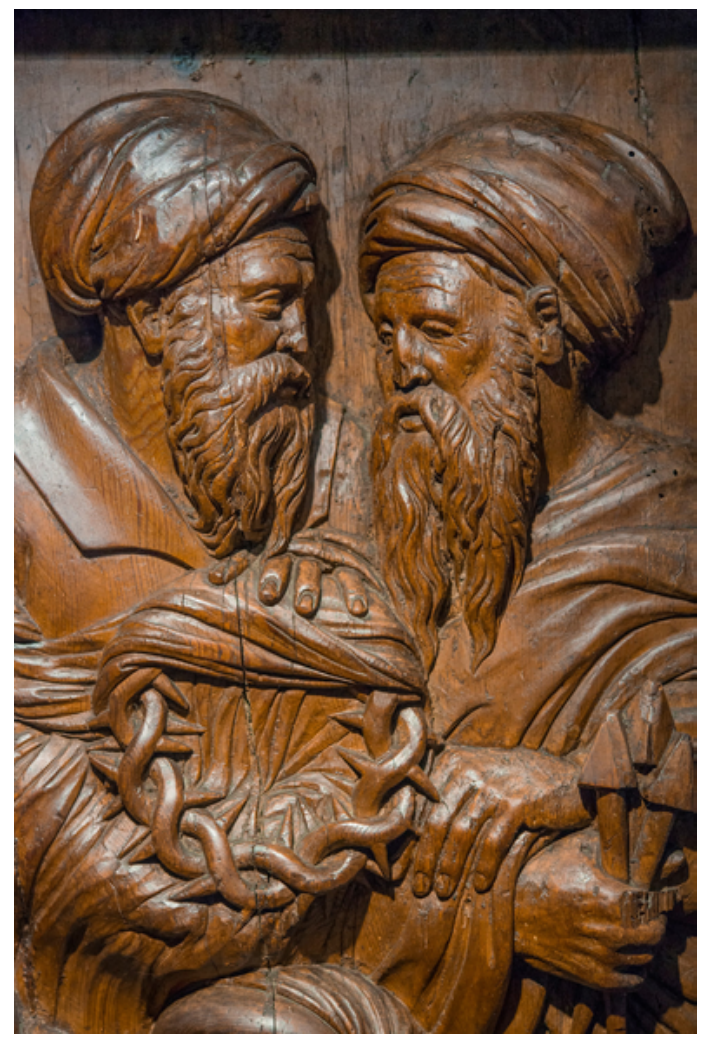

Fig. 10. Atribuido a Roque de Balduque, Lamentación sobre Cristo muerto, ca. 1550, $94 \times 77 \mathrm{~cm}$., Institute of Old Masters Research, Madrid

[Foto: @Institute of Old Masters Research].

\section{CONCLUSIONES}

A modo de conclusión del presente texto, hemos de señalar que no solo el patrimonio de la Villa de Los Realejos -lamentablemente muy mermado como consecuencia de la desamortización y los incendios que han asolado a sus edificios religiosos-, sino también el acervo cultural de Canarias, se enriquece con la recuperación de esta interesante escultura lignaria de san Roque de Montpellier. La misma, debido a sus rasgos, la hemos considerado labor hispalense de uno de los seguidores del flamenco Roque de Balduque, notable figura de la estatuaria hispánica, cuyo peculiar estilo es fruto de su origen nórdico y del poderoso influjo ejercido por la plástica italiana a través del manejo de las fuentes grabadas, especialmente las estampas de Marco Antonio Raimondi. Asimismo, la talla aquí analizada, que arroja una datación de hacia 1560-1580, constituye otra muestra del cuantioso y valioso conjunto de esculturas que, salido de los más afamados obradores sevillanos, arribó a estas 
islas del Atlántico, pudiéndose añadir a la Virgen de la Luz conservada en el Museo de la catedral de La Laguna, hermosa Madonna datada en 1556 y relacionada también con el arte de Balduque (Rodríguez Morales 1999, p. 547) ${ }^{6}$.

EnViado: 29 de agosto de 2021; aceptado: 24 de septiembre de 2021

${ }^{6}$ No queremos concluir este texto sin agradecer al investigador D. José Luis Romero Torres, doctor en Historia del Arte, conservador de Patrimonio Histórico de la Junta de Andalucía y gran conocedor de la escultura andaluza, sus apreciaciones sobre la obra aquí estudiada; al Excmo. Cabildo de Tenerife, al Obispado de San Cristóbal de La Laguna y a la parroquia matriz de La Concepción de Realejo Bajo el gran interés mostrado por la recuperación y reposición al culto de esta interesante imagen del terciario franciscano de Montpellier; y al profesor D. José Nareme Rodríguez Hernández su amable colaboración, por haber realizado y cedido algunas de las fotografías que ilustran el presente estudio. 


\section{BIBLIOGRAFÍA}

Albardonedo Freire, A. (2012). «El Calvario del Cabildo Bajo de la Casa Consistorial de Sevilla: una obra atribuible a Roque de Balduque». Laboratorio de Arte, Sevilla: Universidad de Sevilla, n. 24, t. 2, pp. 795-804.

Bernales Ballesteros, J. (1977a). «Esculturas de Roque Balduque y su círculo en Andalucía y América». Anuario de Estudios Americanos, Sevilla: CSIC, t. Xxxıv, pp. 349-371.

Bernales Ballesteros, J. (1977b). «Esculturas del círculo de Roque de Balduque en Sevilla». Actas del I Congreso Nacional de Historia del Arte (1977), Madrid: Comité Español de Historia del Arte, pp. 35-39.

Castro Brunetto, C.J. (1993). Iconografía franciscana en Canarias. Escultura y pintura. San Cristóbal de La Laguna: Universidad de La Laguna (tesis doctoral inédita).

Estella, M. (1975). «Notas sobre escultura sevillana del siglo Xvi». Archivo Español de Arte, Madrid: CSIC, t. XlviII, n. 190, pp. 225-242.

Estella, M. (2019). «The integration of Italian Renaissance in Spanish sculpture», en Herrero Starkie, C. (ed.), Treasures of Spanish Renaissance Sculpture. The origin of the Spanish manner. Madrid: Institute of Old Masters Research, pp. 75-103.

Fernández de Béthencourt, F. (1959). Nobiliario y Blasón de Canarias. San Cristóbal de La Laguna de Tenerife: Juan Régulo Editor, t. III.

Floriano Cumbreño, A.C. (1940-1941). «El retablo de Santa María la Mayor de Cáceres». BSAA, Valladolid: Universidad de Valladolid, t. viI, pp. 85-95.

Gestoso y Pérez, J. (1908). Ensayo de un diccionario de artifices que florecieron en Sevilla desde el siglo XIII hasta el XVIII. Sevilla: La Andalucía Moderna, vol. III.

Gómez Sánchez, J.A. (2006). «Santiago de Pesquera y Juan Giralte en el Ayuntamiento de Sevilla (1541, 1571)». Laboratorio de Arte, Sevilla: Universidad de Sevilla, n. 19, pp. 67-83.

GonzÁlez Begines, E.J. (2021). La escultura sevillana entre los siglos XVI y XVII. El imaginero Blas Hernández Bello (c. 1560-1627). Granada: Comité Español de Historia del Arte.

GonZÁleZ Y GonZÁleZ, E. (1997). La indumentaria en pinturas en Tenerife de los siglos XVI, XVII y XVII. San Cristóbal de La Laguna: Universidad de La Laguna (tesis doctoral inédita).

Halsema-Kubesh, W. (1971). «Een Mechelse H. Sebastiaan». Bulletin van het Rijksmuseum, Amsterdam: Rijksmuseum, n. 19, pp. 183-188.

Hernández Díaz, J. (1944). «Iconografía hispalense de la Virgen Madre en la escultura renacentista». Archivo Hispalense, Sevilla: Diputación de Sevilla, t. II, n. 3-4, pp. 41-55 y 81-113.

Hernández González, M.J. (2006), «San Roque», en Pérez Morera, J. (comisario), Roque de Montpellier. Iconografía de los santos protectores de la peste en Canarias. Santa Cruz de Tenerife: Gobierno de Canarias, pp. 230-231, cat. 66 [catálogo de la exposición homónima].

Hernández González, S. (2011). «Retablo sacramental», en Ramos Suárez, M.A. (comisario), Tantum Ergo Sacramentum. Fe, Arte y Cultura en Marchena. Sevilla: Parroquia Matriz de San Juan Bautista-Diputación de Sevilla, p. 84 [catálogo de la exposición homónima].

InTERIÁn de Ayala, F.J. (1782). El pintor christiano, y erudito, o tratado de los errores que suelen cometerse freqüentemente en pintar, y esculpir las Imágenes Sagradas. Madrid: Joachín Ibarra, t. II. 
Laguna Pául, T. (2017). «Lorenzo Mercadante de Bretańa (documentado 1446-1468)», en Lechuga Jiménez, C. (ed.), Artistas andaluces y artifices del arte andaluz. El ciclo humanista. Desde el último Gótico al fin del Barroco. A Coruña: Ediciones Comunitarias, pp. 290-325.

López Plasencia, J.C. (2000). «A propósito del V Centenario de San Pedro de Alcántara (14991999). La advocación mariana de Los Afligidos y los franciscanos descalzos de Santa Lucía en la historia religiosa de la Villa de Los Realejos». Revista de Historia Canaria, San Cristóbal de La Laguna: Universidad de La Laguna, n. 182, pp. 127-166.

Palomer Páramo, J. (1983). El retablo sevillano del Renacimiento: análisis y evolución (1560-1629). Sevilla: Diputación de Sevilla.

Parrado del Olmo, J.M. (2019). «Roque de Balduque. Lamentation on the Dead Christ», en Herrero Starkie, C. (ed.), Treasures of Spanish Renaissance Sculpture. The origin of the Spanish manner. Madrid: Institute of Old Masters Research, pp. 334-337.

Porres Benavides, J. (2018). «A propósito de un nuevo San Juan Bautista atribuido a Roque Balduque». Trocadero. Revista de historia moderna y contemporánea, Cádiz: Universidad de Cádiz, n. 30, pp. 317-340.

Ravé, J.L. (2007). La Parroquia de San Juan Bautista de Marchena. Sevilla: Codexsa.

RÉAu, L. (1998). Iconografía del arte cristiano. Iconografía de los santos. De la P a la Z. Repertorios. Barcelona: Serbal, t. 2, vol. 5.

Recio Mir, A. (2009). «La versatilidad del Renacimiento: variedad material, icónica, tipológica y funcional», en Halcón, F., Herrera, F. y Recio, A., El retablo sevillano. Desde sus orígenes a la actualidad. Sevilla: Diputación de Sevilla-Real Maestranza de Caballería-Fundación Cajasol, pp. 69-126.

Roda Peña, J. (2010). «La escultura sevillana a finales del Renacimiento y en los umbrales del Naturalismo», en Gila Medina, L. (coord.), La escultura del primer naturalismo en Andalucía e Hispanoamérica (1580-1625). Madrid: Arco Libros, pp. 273-306.

Roda Peña, J. (2018). «Desde Jorge Fernández a Juan de Mesa: un siglo de crucificados en la escultura sevillana", en Dobado Fernández, P.J. (coord.), Martinez Montañés y el Cristo de los Desamparados. Entre Pablo de Rojas y Juan de Mesa. Sevilla: Samarcanda, pp. 11-47.

Rodríguez-Buzón Calle, M. (2012). La Colegiata de Osuna. Sevilla: Diputación de Sevilla.

Rodríguez Morales, C. (1999). «La Virgen de la Luz de la Catedral de La Laguna (Tenerife) en el arte sevillano del siglo xvi». Anuario de Estudios Atlánticos, Las Palmas de Gran Canaria: Cabildo de Gran Canaria, n. 45, pp. 531-551.

Rojas-Marcos GonzÁlez, J. (2020). «Flandes-Sevilla-Lima: Roque de Balduque (+1561) y la expansión de sus modelos iconográficos en el mundo hispánico», en Parada López de Corselas, M. y Palacios Méndez, L.M. ${ }^{a}$ (eds.), Arte y globalización en el mundo hispánico de los siglos XV al XVII. Granada: Universidad de Granada, pp. 407-425.

Santana Rodríguez, L. (2006). «La huella de San Roque en Tenerife. El Santo de lo nuevo», en Pérez Morera, J. (comisario), Roque de Montpellier. Iconografía de los santos protectores de la peste en Canarias. Santa Cruz de Tenerife: Gobierno de Canarias, pp. 49-68 [catálogo de la exposición homónima].

Santos Márquez, A.J. (2007). «Un retablo del entallador Juan Giralte y el pintor Juan de Zamora». Laboratorio de Arte, Sevilla: Universidad de Sevilla, n. 20, pp. 81-94. 
SAntos Márquez, A.J. (2017). «Sobre el escultor Roque de Balduque y sus trabajos para el IV conde de Ureña, don Juan Téllez Girón». Archivo Hispalense, Sevilla: Diputación de Sevilla, t. c, n. 303-305, pp. 393-404.

Torre Ruiz, M.F. (1992). «Una probable obra de Roque Balduque». Atrio. Revista de Historia del Arte, Sevilla: Universidad Pablo de Olavide, n. 4, pp. 31-33.

Torrico Lorenzo, I. (2017). «San Roque, el peregrino antipestífero de Montpelier». Revista Digital de Iconografía Medieval, Madrid: Universidad Complutense de Madrid, vol. Ix, n. 18, pp. 105-116.

Vorágine S. de la (1997). La leyenda dorada. Madrid: Alianza Forma. 
